\title{
Condylar guidance angles obtained from panoramic radiographic images: An evaluation of their reproducibility
}

\section{Wartości kątów drogi stawowej \\ uzyskiwane ze zdjęć pantomograficznych - ocena powtarzalności metody}

\author{
Jolanta E. Loster ${ }^{A-D, F}$, Aneta Wieczorek ${ }^{B, F}$, Wojciech I. Ryniewicz ${ }^{A, C, E, F}$ \\ Department of Dental Prosthetics, Institute of Dentistry, Jagiellonian University, Kraków, Poland \\ A - research concept and design; B - collection and/or assembly of data; $\mathrm{C}$ - data analysis and interpretation; \\ $D$ - writing the article; $E$ - critical revision of the article; $F$ - final approval of article
}

Address for correspondence

Jolanta E. Loster

E-mail: jolanta.loster@uj.edu.pl

Funding sources

none declared

Conflict of interest

none declared

\section{Acknowledgments}

The authors wish to thank their colleagues from the Prosthodontic Department, Institute of Dentistry, Jagiellonian University in Kraków for their participation in the study.

Received on August 30, 2016

Revised on September 10, 2016

Accepted on September 15, 2016

\begin{abstract}
Background. The method of using panoramic radiographic images to obtain numerical data on the condylar guidance angle has been described in the literature.

Objectives. The aim of the study was to verify the reproducibility of this technique.

Material and methods. One panoramic radiographic image was randomly chosen from a group of 191 images. The digital image was converted to analog and printed. The study involved 21 dentists, who positioned 4 dots on each side of the image (the orbitale and the porion, as well as the most superior and the most inferior points of the jaw's articular surface). The points on each side were connected with 2 lines, $A$ and $B$. To evaluate the accuracy of the lines, the equation of the straight lines was calculated and their slopes compared. The condylar guidance angle between the lines was calculated.
\end{abstract}

Results. The spread of the results for the condylar guidance angle on the right side was 30 degrees; on the left side it was more than 40 degrees. The SD for the slope of line A was 0.01 on both sides. The slope of line $B$ varied from 0.25 to 0.34 .

Conclusions. The use of panoramic images to obtain the condylar guidance angle is not recommended in clinical use.

Key words: reproducibility, guidance angle, panoramic image, condylar guidance

Słowa kluczowe: powtarzalność metody, kąt stawowy, zdjęcie tomograficzne, droga stawowa

DOI

$10.17219 / \mathrm{dmp} / 65837$

Copyright

○) 2017 by Wroclaw Medical University

and Polish Dental Society

This is an article distributed under the terms of the

Creative Commons Attribution Non-Commercial License

(http://creativecommons.org/licenses/by-nc-nd/4.0/) 
The definition of condylar guidance that appears in The Glossary of Prosthodontic Terms has two parts. ${ }^{1}$ The first is anatomical, and is expressed in terms of the glenoid fossae, which are bone parts of the skull. The second part focuses on the mechanical relationship between the parts of the articulator. This clearly shows the application of clinical data to prosthetic laboratory procedures with the aim of duplicating jaw function and the occlusal relationship of the teeth.

Different clinical procedures have been used to obtain the numerical data for individual condylar guidance values. Some of these require intraoral wax records or extraoral measurements using pantographic equipment. ${ }^{2-8}$ The study by Gilboa et al. introduced the method of using panoramic images in a clinical setting to provide the anatomical incline of the auricular eminence. ${ }^{9}$ This method generated much interest and was encouraged on account of its simplicity and availability. Panoramic images are among the most frequently made radiographic examinations before the treatment is planned. ${ }^{10-12}$ Using this method, Gilboa et al. obtained a mean difference in the inclination of the condylar guidance angle of 7 degrees. ${ }^{13}$ In the molar area, such a discrepancy could lead to a difference in position of the mandible of 0.25 to $0.5 \mathrm{~mm}$. The pilot study of Tannamala et al. compared the condylar angles set in the semi-adjustable articulator using an intraoral protrusive record to those from the panoramic radiographic image, and showed that the method is a simple and easy way to program the articulators and is capable of producing clinically acceptable restorations. ${ }^{14}$ The study was performed on a group of 10 patients who were free of the signs and symptoms of temporomandibular disorders, and who also possessed intact dentition. The study involved different individuals, with specific anatomy, and each image was examined only once; the condylar angles were compared, with results being received after intraoral registration. The results for the condylar angles vary with the patients' sides and the methods of calculation. Some results were greater on both sides in the radiographic method, some were greater on one side, and some were smaller. The reproducibility of the radiographic method was not evaluated here, and the authors suggested that further studies should be carried out. We conducted a study to evaluate the reproducibility of that method in a group of final-year dental students. Using the described method, these students analyzed a single radiographic image. ${ }^{9}$ The results proved inadequate from the clinical point of view. ${ }^{15}$ To verify the method in the group of more experienced dental practitioners, the present study was implemented.

The aim of the study was to compare the condylar guidance angles obtained by different dentists from the same panoramic radiographic image, and to investigate the problems of the method where discrepancies were found in the results.

\section{Material and methods}

One panoramic radiographic image was randomly chosen from a group of 191 images produced during examinations of volunteers who had participated in a larger research project. These volunteers were free of the signs and symptoms of temporomandibular disorders, as determined by the Polish version of the Research Diagnostic Criteria for Temporomandibular Disorders (RDC/TMD) questionnaire; they also possessed intact dentition. ${ }^{16,17}$ All the participants expressed their unforced consent to participate in the study and signed the appropriate statement. The examination was performed in accordance with the Declaration of Helsinki and Good Clinical Practice (GCP). The consent of the Bioethics Committee of the Jagiellonian University, Kraków, Poland, was obtained (number KBET/89/B/2009).

The panoramic radiographic image was taken with the Frankfurt horizontal plane parallel to the floor of the mouth; a cephalostat was used to align the head in that position, as in Tannamala et al. ${ }^{14}$ The radiograph was made using a ProMax ${ }^{\circledR}$ radiographic unit (Planmeca, Helsinki, Finland 2005) at $74 \mathrm{kVp}$ and $10 \mathrm{~mA} .9,14$

The method was the same as that described previously by Loster et al..$^{15}$ The chosen digital image was converted to analog and printed on A4 size (ISO 216) paper using an Epson Stylus Photo 1400 (Seiko Epson Corporation, Japan, 2007) inkjet printer; the resolution used was 2880 $\times 1440$ dots per inch. One copy was provided to each of the participants, who were recruited from the Prosthodontic Department of the Jagiellonian University. All the departmental members gave their verbal voluntary consent to participate in the study. The prosthodontists (SP), trainees ( $\mathrm{T}$ ), and general dental practitioners (GDP) who contributed to the study were asked to place dots in 4 places on both sides of the printed standardized panoramic radiographic image. Prior to this, definitions of the expected points (the orbitale and porion) were presented to the participants. Afterwards, an image from Gilboa et al. was presented to illustrate the differences between the position of the zygomatic arch and the auricular eminence on the panoramic radiographic image. ${ }^{9}$ The participants were then asked to mark the most superior point of the mandibular fossa and the most inferior point of the curvature of the articular tubercle, following the procedure of Tannamala et al. ${ }^{14}$ The study was conducted simultaneously with all participants. The annotated photographs were numbered and scanned (Digital Photo Scanner Epson Perfection V370 Photo, Seiko Epson Corporation, Japan, 2012) to produce a digital image. A scanning resolution of 1440 dots per inch was used. The coordinates of the measuring points were then determined. The zero (0.00) point was set to the left-upper corner of each image. Using Adobe Photoshop CS2, the orbitale $\mathrm{O}\left(\mathrm{X}_{\mathrm{O}}, \mathrm{Y}_{\mathrm{O}}\right)$ and porion $\mathrm{P}\left(\mathrm{X}_{\mathrm{P}}, \mathrm{Y}_{\mathrm{P}}\right)$ points were connected 


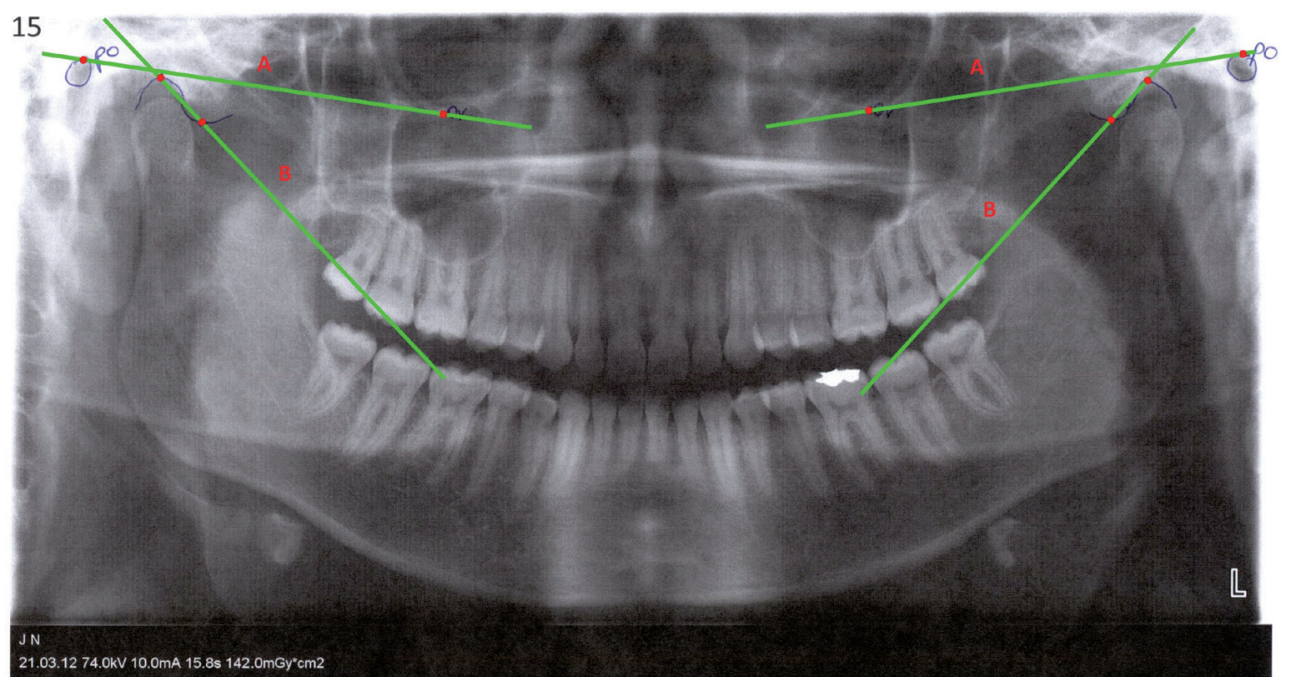

Fig. 1. Example of a radiographic image marked with four dots (in red) and connected by lines $\mathrm{A}$ and $\mathrm{B}$ by a line marked $\mathrm{A}$ to the Frankfurt horizontal plane. The most superior point, $\mathrm{W}\left(\mathrm{X}_{\mathrm{W}}, \mathrm{Y}_{\mathrm{W}}\right)$, and the most inferior point, $\mathrm{N}\left(\mathrm{X}_{\mathrm{N}}, \mathrm{Y}_{\mathrm{N}}\right)$, of the curvatures were connected with the mean curvature line (that is, the mean condylar path inclination) by line $\mathrm{B}$, following Tannamala et al. ${ }^{14}$ This procedure was carried out on both sides of each image (see Fig. 1 for an example).

To evaluate the accuracy of each line, the equation of the line, $y=a x+b$, was used, with "a" representing the slope and " $b$ " the $y$-intercept. We calculated the slope of each line in order to compare the repeatability of the points. The points $\mathrm{O}$ and $\mathrm{P}$ were thus on the same line $\mathrm{A}$, and the equations of these lines $\mathrm{A}$ can be written as:

$$
\mathrm{Y}_{\mathrm{O}}=\mathrm{a}_{\mathrm{OP}} \mathrm{X}_{\mathrm{O}}+\mathrm{b}_{\mathrm{OP}} \text { and } \mathrm{Y}_{\mathrm{P}}=\mathrm{a}_{\mathrm{OP}} \mathrm{X}_{\mathrm{P}}+\mathrm{b}_{\mathrm{OP}}
$$

where the slope of $\mathrm{A}$ is:

$$
\mathrm{a}_{\mathrm{OP}}=\left(\mathrm{Y}_{\mathrm{P}}-\mathrm{Y}_{\mathrm{O}}\right) /\left(\mathrm{X}_{\mathrm{P}}-\mathrm{X}_{\mathrm{O}}\right)
$$

and the slope of $B$ (which passes through points $\mathrm{N}$ and $\mathrm{W}$ ) is:

$$
\mathrm{a}_{\mathrm{WN}}=\left(\mathrm{Y}_{\mathrm{N}}-\mathrm{Y}_{\mathrm{W}}\right) /\left(\mathrm{X}_{\mathrm{N}}-\mathrm{X}_{\mathrm{W}}\right) .
$$

A discrepancy between the slope values would be significant for the reproducibility of the pairs of analyzed points.

The condylar guidance angle between the lines A and $B$ was calculated using the equation:

$$
\tan \varphi=\left|\frac{a_{O P}-a_{W N}}{1+a_{O P} \times a_{W N}}\right|
$$

and then the angle:

$$
\varphi=\arctan \left|\frac{a_{O P}-a_{W N}}{1+a_{O P} \times a_{W N}}\right|
$$

\section{Statistical analysis}

All the data was analyzed using Statistica data analysis software v. 10 (StatSoft, Inc., 2011; www.statsoft.com). Data normality was tested using the Shapiro-Wilk test. Homogeneity was tested using Levene's test. The descriptive statistics and ANOVA test were used, and the multiple independent samples were compared using the Kruskal-Wallis U-test. The results are shown in the tables and charts. The level of statistical significance was set at $5 \%(\mathrm{p}=0.05)$.

\section{Results}

Twenty-one dentists participated in the study; of these, 7 were specialists in prosthodontics (SP), 8 were trainees (T), and 6 were general dental practitioners (GDP). The marks from 1 trainee were excluded from the analysis due to outlying results. The average value, median, standard deviation, minimum, and maximum for the slopes of the line $A$ on both sides are presented in Tables 1 and 2. In Tables 3 and 4, the same data is shown for the slopes of line $\mathrm{B}$. The slope values for both lines and for both sides did not significantly differ between the groups of participants. The dispersion in the slopes of lines A and B, separately on both sides, is graphically presented for all participants in Fig. 2. The minimum and maximum values of the condylar guidance angle determined by each group of participants are presented in Fig. 3.

\section{Discussion}

The results show that the method developed by Gilboa et al. ${ }^{9}$ of using panoramic images to obtain the condylar guidance angle is unacceptable in dental practice. In each 
Table 1. Slope of the line A (right side)

\begin{tabular}{|c|c|c|c|c|c|}
\hline & Average & Median & SD & Min & Max \\
\hline SP & 0.14 & 0.14 & 0.02 & 0.11 & 0.15 \\
\hline $\mathrm{T}$ & 0.14 & 0.14 & 0.01 & 0.12 & 0.16 \\
\hline GDP & 0.14 & 0.14 & 0.02 & 0.11 & 0.16 \\
\hline Mean & 0.14 & 0.14 & 0.01 & 0.11 & 0.16 \\
\hline $\begin{array}{l}\text { Kruskal-Wallis } \\
\text { U-test; } p=0.9349\end{array}$ & & & & & \\
\hline
\end{tabular}

SP - specialists in prosthodontics; $T$ - trainees; GDP - general dental practitioners; SD - standard deviation.

Table 2. Slope of the line A (left side)

\begin{tabular}{|c|c|c|c|c|c|}
\hline & Average & Median & SD & Min & Max \\
\hline SP & -0.13 & -0.13 & 0.01 & -0.14 & -0.11 \\
\hline T & -0.14 & -0.14 & 0.01 & -0.15 & -0.12 \\
\hline GDP & -0.13 & -0.13 & 0.01 & -0.15 & -0.12 \\
\hline Mean & -0.13 & -0.13 & 0.01 & -0.15 & -0.11 \\
\hline $\begin{array}{l}\text { Kruskal-Wallis } \\
\text { U-test; } p=0.3505\end{array}$ & & & & & \\
\hline
\end{tabular}

SP - specialists in prosthodontics; T - trainees; GDP - general dental practitioners; SD - standard deviation.

Table 3. Slope of the line B (right side)

\begin{tabular}{|c|c|c|c|c|c|}
\hline & Average & Median & SD & Min & Max \\
\hline SP & 0.84 & 0.86 & 0.20 & 0.58 & 1.14 \\
\hline T & 0.92 & 0.94 & 0.13 & 0.70 & 1.06 \\
\hline GDP & 0.93 & 0.92 & 0.40 & 0.42 & 1.46 \\
\hline Mean & 0.89 & 0.92 & 0.25 & 0.42 & 1.46 \\
\hline $\begin{array}{l}\text { Kruskal-Wallis } \\
\text { U-test; } p=0.7446\end{array}$ & & & & & \\
\hline
\end{tabular}

SP - specialists in prosthodontics; T - trainees; GDP - general dental practitioners; SD - standard deviation.

Table 4. Slope of the line B (left side)

\begin{tabular}{|c|c|c|c|c|c|}
\hline & Average & Median & SD & Min & Max \\
\hline$S P$ & -0.70 & -0.85 & 0.39 & -1.25 & -0.11 \\
\hline T & -0.98 & -0.93 & 0.20 & -1.23 & -0.65 \\
\hline GDP & -0.81 & -0.93 & 0.40 & -1.23 & -0.08 \\
\hline Mean & -0.83 & -0.89 & 0.34 & -1.25 & -0.08 \\
\hline $\begin{array}{l}\text { Kruskal-Wallis } \\
\text { U-test; } p=0.3735\end{array}$ & & & & & \\
\hline
\end{tabular}

SP - specialists in prosthodontics; T - trainees; GDP - general dental practitioners; SD - standard deviation.

group of participants in this investigation, the standard deviation (SD) of the angular value was above 4 degrees. The clinical use of this method would, therefore, seem to be not indicated. The spread of the values of the condylar guidance angle in the results on the right side was 30 degrees, while on the left side it was more than 40 degrees. There were no significant statistical differences between the groups of dentists. In clinical use, this means that the difference in the molar region would be more than $1 \mathrm{~mm}$, following Craddock's results, which showed that a positive 10 degree change in the condylar guidance angle would move the molars $0.5 \mathrm{~mm}$ further, while a negative 10 degree change would bring the mandible $0.5 \mathrm{~mm}$ closer. $^{13}$ In Weinberg's results, a 9-degree decrease in the condylar guidance angle resulted in a $0.2 \mathrm{~mm}$ reduction in the nonworking cusp height. ${ }^{18}$ Such differences, which 


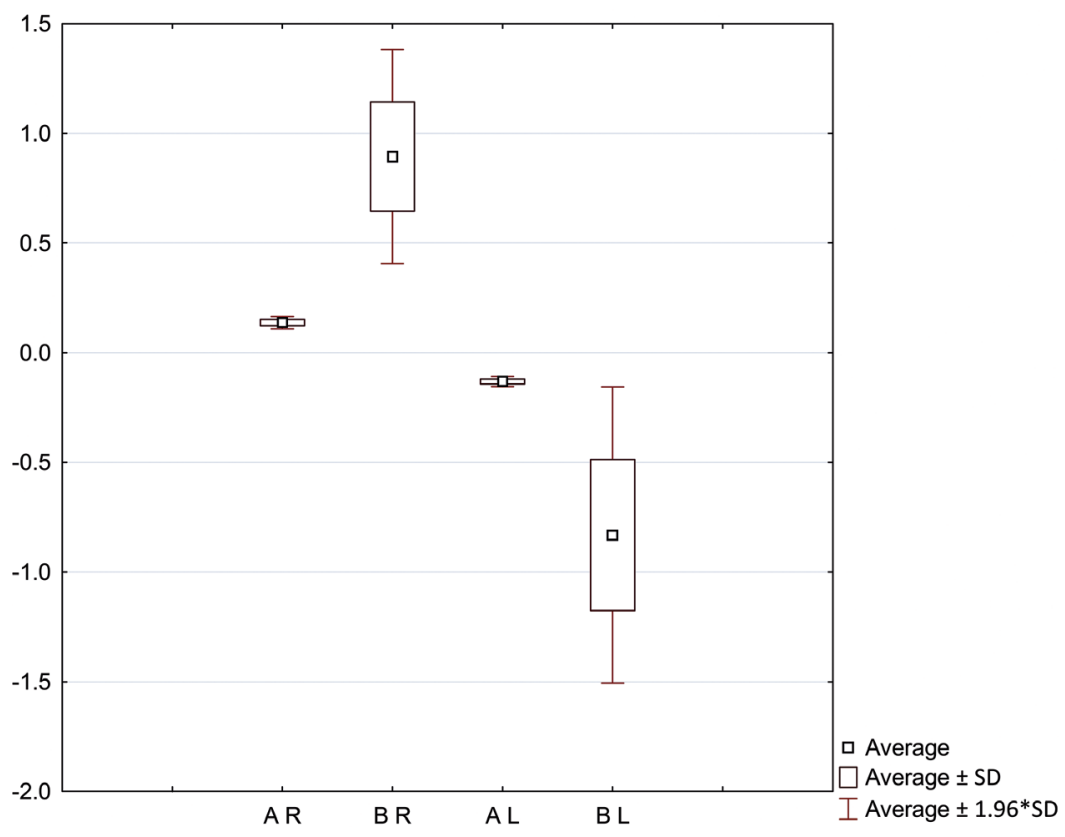

Fig. 2. Average value of slopes of lines $A$ and $B$ on both sides, all participants. AR: slope of line A on the right side; BR: slope of line B on the right side; $A L$ : slope of line $A$ on the left side; $B L$ : slope of line $B$ on the left side

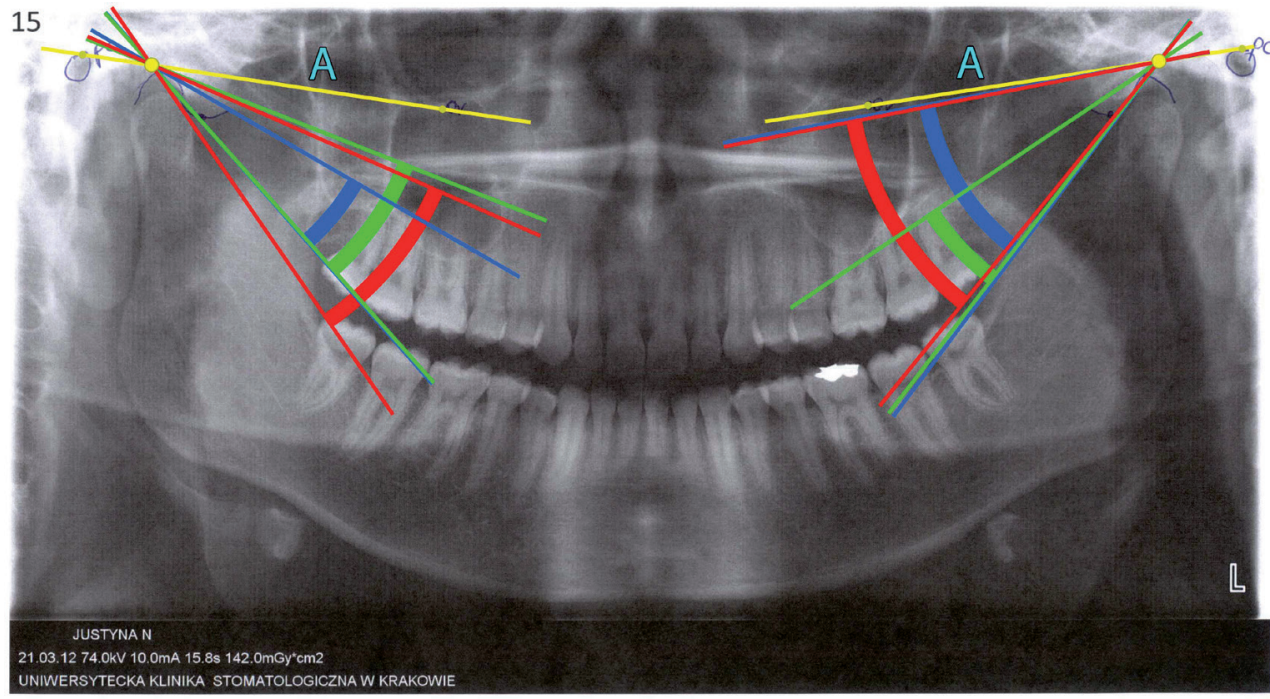

Fig. 3. The range of condylar guidance angles (minimum and maximum values) obtained by each group of participants on both sides. Yellow line - line A; blue lines: SP condylar guidance angle range of values; green lines: T condylar guidance angle range of values; red lines: GDP condylar guidance angle range of values; T: trainees; SP: specialists in prosthodontics; GDP: general dental practitioners

were indeed found in this study, may lead to occlusal disturbances in prosthetic restorations in an articulator setting.

The cause of this imprecision in the angle value was the lack of accuracy in drawing one pair of the examined points. After analyzing the slopes of the lines that subtend the condylar guidance angle, it was shown that the inaccuracy in the results arose from the nonrepeatable designation of the points on line B, presented in Fig. 1 and explained in Fig. 2. These are the most superior and the most inferior points of the curvatures that create the jaw's articular surface, temporal eminence, and fossa. These structures are not very visible on the panoramic radiographic image. Even the study by Gilboa et al. ${ }^{9}$ showed the localization of the articular tubercle very well, compared to the zygomatic arch; the most superior point, located in the mandibular fossa, is not easy to recognize in the panoramic image. The standard deviation in the slope of line $\mathrm{A}$ in the present study was 0.01 on both sides, which can be compared with the slope of B, which varied from 0.25 to 0.34 (Tables $1-4$ ). Very similar results were presented in our previous investigation, where much less experienced final-year dental students were included. ${ }^{15}$

In the research of Prasad et al. the values for the condylar guidance angle obtained from the panoramic image were compared with those from the semi-adjustable articulators by using the protrusive interocclusal records of 69 patients. ${ }^{19}$ The average of 2 examiners' results was taken as the condylar guidance angle. These examiners calculated the angle using the same method described above. Interexaminer reliability was very high. The examiners 
concluded that this method of calculating the condylar guidance angle from a radiographic image may have clinical relevance in setting the condylar guidance settings for semi-adjustable articulators. Going by our results, their results were too optimistic and it would be interesting to see the results of the panoramic radiography evaluated by more researchers.

On the other hand, the average value for the condylar guidance angle obtained using the method described here was about 30 degrees. It may be that this method would be useful for population screening studies. Further investigations in this field are also recommended.

On the basis of our results, the use of panoramic images in calculating the condylar guidance angle is not recommended in clinical use due to lack of repeatability of its results.

\section{References}

1. The glossary of prosthodontic terms. J Prosthet Dent. 2005;94:10-92.

2. dos Santos J Jr, Nelson S, Nowlin T. Comparison of condylar guidance setting obtained from a wax record versus an extraoral tracing: A pilot study. J Prosthet Dent. 2003;89:54-59.

3. Ogawa T, Koyano K, Suetsugu T. The influence of anterior guidance and condylar guidance on mandibular protrusive movement. J Oral Rehabil. 1997;24:303-309.

4. Petrie CS, Woolsey GD, Williams K. Comparison of recordings obtained with computerized axiography and mechanical pantography at 2 time intervals. J Prosthodont. 2003;12:102-110.

5. Pelletier LB, Campbell SD. Comparison of condylar control settings using three methods: A bench study. J Prosthet Dent. 1991;66:193-200.

6. Thakur M, Jain V, Parkash H, Kumar P. A comparative evaluation of static and functional methods for recording centric relation and condylar guidance: A clinical study. J Indian Prosthodont Soc. 2012;12:175-181.
7. Galagali G, Kalekhan SM, Nidawani P, Naik J, Behera S. Comparative analysis of sagittal condylar guidance by protrusive interocclusal records with panoramic and lateral cephalogram radiographs in dentulous population: A clinico-radiographic study. J Indian Prosthodont Soc. 2016;16:148-153.

8. Shreshta P, Jain V, Bhalla A, Pruthi G. A comparative study to measure the condylar guidance by the radiographic and clinical methods. J Adv Prosthodont. 2012;4:153-157.

9. Gilboa I, Cardash HS, Kaffe I, Gross MD. Condylar guidance: Correlation between articular morphology and panoramic radiographic images in dry human skulls. J Prosthet Dent. 2008;99:477-482.

10. Wieczorek A, Loster J, Majewski S. Assessment of suitability of orthopantomographs in dental diagnostics of temporomandibular joints. J Stoma. 2012;65:845-854.

11. Napier ID. Reference doses for dental radiography. Br Dent J. 1999;186:392-396.

12. Williams JR, Montgomery A. Measurement of dose in panoramic dental radiology. Br J Radiol. 2000;73:1002-1006.

13. Craddock FW. The accuracy and practical value of records of condyle path inclination. J Am Dent Assoc. 1949;38:697-710.

14. Tannamala PK, Pulagam M, Pottem SR, Swapna B. Condylar guidance: Correlation between protrusive interocclusal record and panoramic radiographic image: A pilot study. J Prosthodont. 2012;21: 181-184.

15. Loster JE, Ryniewicz W, Ryniewicz J, Wieczorek A. Assessment of the repeatability of condylar guidance angles obtained from panoramic radiographic images. J Stoma. 2014;67:841-849.

16. Loster JE, Osiewicz MA, Groch M, Ryniewicz W, Wieczorek A. The prevalence of tmd in polish young adults. J Prosthodont. $2015 \mathrm{Dec} 8$. Available from: http://www.ncbi.nlm.nih.gov/pubmed/26646470.

17. Osiewicz MA, LobbezooF, Loster BW, Wilkosz M, Naeije M, Ohrbach R. Research diagnostic criteria for temporomandibular disorders ( $\mathrm{rdc}$ / tmd) - the polish version of a dual-axis system for the diagnosis of tmd. Rdc/tmd form. J Stoma. 2013;66:576-649.

18. Weinberg LA. An evaluation of basic articulators and their concepts. Part II: Arbitrary, positional, semiadjustable articulators. J Prosthet Dent. 1963;13:645-663.

19. Prasad KD, Shah N, Hegde C. A clinico-radiographic analysis of sagittal condylar guidance determined by protrusive interocclusal registration and panoramic radiographic images in humans. Contemp Clin Dent. 2012;3:383-387. 